\title{
Um Argumento a Favor da ExistênCia de Deus Formulado por Pierre Duhem ${ }^{1}$
}

\author{
Fábio Rodrigo Leite ${ }^{2}$
}

\begin{abstract}
RESUMO: O objetivo deste artigo é examinar o que entendemos ser uma prova original da existência de Deus na obra de Pierre Duhem. Cremos que a originalidade dessa prova consiste especialmente nas premissas usadas pelo filósofo. Quanto à forma, a mesma assemelha-se ao conhecido argumento do designio, mas a sua versão se caracteriza por buscar na história das teorias fisicas a matéria da qual a existência de uma Providência é derivada. É a complexa evolução das teorias e, a despeito dela, a sua espantosa progressividade em direção a estágios sempre mais perfeitos que servem de premissa para a via duhemiana de acesso a Deus. Tudo se passa como se houvesse uma suposta pré-ordenação divina do curso das teorias, uma finalidade intrínseca a ele.
\end{abstract}

PALAVRAS-CHAVE: História. Teorias físicas. Estática. Desígnio. Deus.

\section{INTRODUÇÃo}

Ao passo que Abel Rey (1904) insistiu na existência de uma "filosofia científica” duhemiana, André Darbon (1928, p. 504) ressaltou sabiamente que nosso autor não tem apenas uma história das ciências, mas uma verdadeira “filosofia da história”. Já tentamos, em outra ocasião (LEITE, 2012, p. 117186), delinear os principais traços dessa filosofia, e o que aqui expomos é somente uma parte daquela leitura, embora um tanto desenvolvida. São pouquíssimos, aliás, os trabalhos que se incumbem de esquadrinhar a filosofia da história de Duhem e, mesmo entre os que aceitam o encargo, a quase totalidade relega a um plano secundário as reflexóes do físico francês atinentes à realidade de uma Providência divina ${ }^{3}$. Nosso objetivo principal, neste artigo, é encetar o preenchimento dessa lacuna.

\footnotetext{
${ }^{1}$ http://dx.doi.org/10.1590/S0101-31732016000400003

${ }^{2}$ Doutor em Filosofia da Ciência pela FFLCH-USP (2012). E-mail: efferrelle@yahoo.com.br.

${ }^{3} \mathrm{O}$ exame da filosofia da história duhemiana feito por Chiappin e Leister (2009), por exemplo, não toca na questáo; o livro de Paul Brouzeng (1987), apesar do título sugestivo, Duhem: science et providence, analisa a apologética de Duhem de uma perspectiva historiográfica e menos filosófica; Harry Paul (1979, p. 176) e Jean-François Stoffel (2002, p. 311-312) mencionam en passant o excerto de Les origines de la statique, o qual nos estimulou a escrever o presente artigo. Darbon (1928), Jaki (1984) e Maiocchi (1985) são exceçóes, contudo, nenhum deles, mormente o primeiro, se detém
} 
Caracterizar a filosofia da história abraçada por Duhem como otimista, ainda que não iluminista, não deixa de ser correto. Contrariando a tradição das Luzes, de matiz condorcetiano, o historiador evita crer que a humanidade esteja condicionada a um desenvolvimento intelectual de suas capacidades (DUHEM, 1915, p. 93). É grande a presunção daqueles que acreditam que raciocinamos melhor que nossos antepassados, que estes viveram numa época da infância da humanidade e que nós, altaneiros, atingimos um estágio de superioridade mental. A perfectibilidade não faz parte das aptidóes humanas, de sorte que o grego antigo e o francês contemporâneo dividiriam o mesmo patamar. Essa negativa inicial, porém, não implica a recusa de uma perspectiva progressista da história da ciência. Se as capacidades produtoras do conhecimento permanecem as mesmas, esse mesmo conhecimento pode avançar.

A visão do progresso como essencialmente revolucionário repugna ao espírito conservador de Duhem (BROUZENG, 1987, p. 11), para quem o respeito pela tradição é uma das regras fundamentais para a sadia evoluçáo da ciência (DUHEM, 1905-1906, v.1, p. iv)4. A perspectiva organicista é-lhe mais cara. A história evoluiria como um organismo vivo e, como tal, caminharia lenta e gradualmente, em meio à complexidade sempre crescente, para uma direção determinada, segundo um plano prévio pautado pela harmonia entre seus sucessivos estados. Assim concebida, a evolução das teorias físicas (é sempre da história das teorias que estaremos a tratar) condulo a uma imagem virtualista da história, segundo a qual os estágios futuros de seu desenvolvimento estão potencialmente contidos nas fases iniciais da evolução, e que deve haver uma inteligência responsável pelo agenciamento e pela manutençáo da ordem. Em meio ao caos aparente, o historiador de olhos apurados é capaz de revelar uma fina ordem, um plano arquitetônico prévio, o qual serve de diretriz às transformaçôes temporais das teorias. Os indícios desse plano, obra da Providência, podem ser identificados especialmente em duas ocasióes: (a) no valor positivo dos erros, uma vez que mesmo as teorias errôneas do passado parecem ter contribuído para a obtenção futura de teorias mais bem fundamentadas, e (b) na convergência harmônica das relaçóes físico-matemáticas, ajustadas tão perfeitamente na evolução teórica que isso

em seu estudo. A nosso ver, o panorama mais detalhado foi aquele descrito por Maiocchi (1985, p. 258-264). Entrementes, ele permanece estreitamente vinculado a uma visão parcial do continuísmo histórico duhemiano, recusado por nós (LEITE, 2012, p. 261-273). Por isso, não retomaremos aqui as conclusōes do intérprete italiano.

${ }^{4}$ Para um exame do conservadorismo metodológico de Duhem, cf. Leite (2012, p. 273-285). 
não poderia, insiste Duhem, resultar do simples acaso, mas de uma força de atração superior e inconsciente inclusive aos criadores das teorias particulares. Vejamos isso com maior cuidado.

\section{Precedentes do argumento duhemiano}

São raras as oportunidades nas quais Duhem se refere a Deus ou às ações providenciais Deste em seus escritos. A bem da verdade, as referências que nos interessam são invariavelmente oblíquas e estáo sempre localizadas nas conclusóes de artigos e livros, como que servindo de arremate às longas exposiçóes históricas. Em todos os casos, a ideia que guia a introdução da providência divina é a existência de uma orientação subjacente às transformaçóes sofridas pelas teorias físicas no decurso dos acontecimentos. As quatro ocorrências que desejamos relevar, em ordem cronológica de escrita, são estas: (1) "Celui", em "L'évolution des théories physiques du XVIIe siècle jusqu’à nos jours" (DUHEM,1896, p. 499); (2) "Idée directice", em L'évolution de la mécanique (DUHEM,1903, p. 345); (3) "Sagesse", "Puissance", "Providence" e "Idée directrice", em Les origines de la statique (DUHEM, 1905-6, v.2, p. 290); e, novamente, (4) "Celui", no primeiro volume dos Études sur Leonard de Vinci (DUHEM, 1906, v.1, p. 2535). Excetuada a terceira oportunidade, nenhuma das demais pode ser considerada exatamente uma argumentação a favor da existência de Deus, embora seja conveniente introduzirmos uma curta exposição das duas primeiras, para que possamos compreender melhor a emergência da terceira.

"L'évolution des théories physiques" é o último dos textos que compóem uma série de artigos publicados desde 1892, nas páginas da Revue des questions scientifiques, a qual tinha por objeto apresentar as reflexóes inaugurais do filósofo acerca do valor das físicas teórica e experimental ${ }^{6}$. Já reconhecido

\footnotetext{
${ }^{5}$ Essa ocorrência, a qual passou despercebida pelos comentadores que se preocuparam com o assunto, dá-se num parágrafo isolado dos anteriores, ao fim do último artigo nâo inédito que viria a ser incluído no primeiro volume dos Études sur Léonard de Vinci. Após mostrar que plagiários, como Cardano, contribuíram para preservar e difundir a obra de Da Vinci, o autor acrescenta: "Aquele [Celui] que conduz os pensamentos humanos faz as mais tristes fraquezas dos cientistas [savants] servirem ao progresso da ciência." Examiná-la aqui com pormenores nos desviaria do foco proposto.

${ }^{6}$ A escolha da Revue não ocorreu por acaso. Atendendo ao convite do colega Paul Mansion (HILBERT, 2000, p. 66), sucessor de Carbonnelle no cargo de secretário geral da Revue, desde 1890, Duhem decidiu ali divulgar suas ideias por um segundo motivo. A revista era publicada sob os auspícios da Société Scientifique de Bruxelles, organização católica, em que pese o nome neutro, da qual ele era membro desde 1891 (JAKI, 1984, p. 92) e da qual veio a assumir o cargo de vice-presidência, em
} 
como físico teórico, o jovem professor sabia como desconstruir o positivismo extremado a partir do seu interior, relativizando o valor de saber da física teórica e impedindo-a de avançar sobre o terreno da metafísica e da religião (DUHEM, 1989b; LEITE, 2016). Uma de suas teses mais importantes concernia ao esvaziamento do conteúdo ontológico das teorias físicas, doravante vistas como instrumentos de auxílio à memória, cuja finalidade consistia na simples representação e classificação convencionais das leis experimentais (DUHEM, 1989a). Das teorias estaria excluído qualquer objetivo que visasse à investigação das causas inobserváveis daquelas leis. A busca das essências ficaria reservada exclusivamente à metafísica.

Todavia, no transcorrer da história, Duhem reconhece-o de pronto, nem sempre os preceitos acima teriam sido observados, principalmente nos três últimos séculos, época em que o mecanicismo, em suas variadas versóes realistas, teria dominado as opiniôes dos sábios (DUHEM, 1896; LEITE, 2012, p. 285-304). Demasiado pretensiosos, os mecanicistas modernos, entre eles os cartesianos, atomistas e dinamistas (seguidores de Newton), intentavam conhecer de início a essência da matéria para, a seguir, explicar os fenômenos observados em função das propriedades da primeira. Uma de suas exigências de inteligibilidade explicativa residia na exclusão das qualidades do domínio das teorias com a redução das mesmas à pura categoria da quantidade. As aparências, ou efeitos, não eram registradas, mas explicadas a partir das características últimas e supostamente irredutíveis da matéria, identificadas, no mais das vezes, com as grandezas estudadas pela geometria. Consultada com vagar, a história que desvela a proeminência recente do falso método físico - o método sintético (DUHEM, 1903, p. 180) - é a mesma que patenteia a sua predominância provisória, fadada à decadência. A evolução das teorias não se sujeita, assevera Duhem, aos anseios do mecanicismo, o qual sucumbe ao teste do tempo. Sobre uma base tão restrita, nenhuma teoria compreensiva e duradoura poderia ser elaborada. O surpreendente desfecho da longa narrativa das vicissitudes que afligiram a física, nos últimos três séculos, é feito, em "L'évolution des théories physiques", com estas palavras:

Impaciente para abandonar o campo no qual a física da Escola o havia trancado, o espírito humano empregou três séculos e milhares de cientistas

1900 (HILBERT, 2000, p. 67). Para uma breve exposição sobre as relações entre Duhem e o programa apologético da Société, cf. Stoffel (2002, p. 329-335); para uma história mais geral da Revue, cf. Nye (1976); Jaki (1984, p. 92-93); para um histórico resumido da importante série de Congressos promovidos pela Société, nos fins do século XIX (Duhem participou destacadamente do terceiro), cf. Hilbert (2000, p. 125-133). 
[savants] para abrir uma rota na direção da verdadeira ciência do mundo material. A direção desta rota mudou com frequência e, atualmente, constatamos com espanto que ela se fecha sobre si mesma e nos reconduz ao ponto de partida. E, entretanto, nesse imenso labor, não há um trabalhador cuja obra tenha-se perdido; não que esta obra tenha sempre servido ao que seu autor a destinou; o papel que ela desempenha na ciencia atual difere constantemente do papel que ele lhe atribuira; ela ocupou o lugar que Aquele que conduz toda essa agitação havia marcado antecipadamente. (DUHEM, 1896, p. 499, grifo nosso).

O espanto ao qual o autor se refere tem como causa a - alentadora - degeneração do projeto mecanicista, a qual significa o retorno inesperado ao ponto de partida, isto é, a uma física das qualidades, pré-reducionista, que não procura reduzir todas as propriedades físicas a grandezas geométricas (figura, extensão e movimento). A termodinâmica dos fins do século XIX, "[...] uma das mais perfeitas teorias físicas," (DUHEM, 1989a, p. 25), simboliza esse retorno, ao acrescentar novas propriedades macroscópicas (qualidades) às suas grandezas "primitivas". É nesse sentido que a física retorna à forma qualitativa de Aristóteles, depois de muito oscilar entre variegadas tendências mecanicistas ${ }^{7}$. Após a revolução cartesiana que baniu as qualidades da física, um retorno gradual à física das qualidades foi sendo operado. Digno de nota é o fato de que, em vez de explicar esse retorno como o resultado da aplicação da metodologia instrumentalista, reduzindo o problema da "eficiência" a um problema de método, Duhem dirija a sua atençâo para um outro aspecto da evolução - a preservação ou o destino das obras dos físicos, em um contexto desconhecido por eles. Preocupa-lhe o legado positivo a despeito de seus promotores particulares, pois exclusivamente assim a disposição desse legado pode ser transferida Àquele que estipula antecipadamente o seu devido lugar.

Essa noção cartogramática do (re)arranjo das descobertas individuais em um "ajuste fino", cada dia mais explícito, explica por que os mecanicistas, vencidos, não trabalharam inutilmente. A termodinâmica é também tributária do matematismo cartesiano, herdeira da síntese newtoniana e do método

\footnotetext{
${ }^{7} \mathrm{Na}$ remissão a Aristóteles reside a segunda erupção apologética provocada pela admoestaçấo, feita um ano antes por Bulliot, para que Duhem contribuísse da maneira que lhe conviesse com a causa católica (STOFFEL, 2002, p. 321-327). Trata-se da primeira oportunidade de uma série de ensaios comparativos entre a física dos fins do século XIX e a física peripatética, a qual culminará no artigo "Physique de croyant". Se é "absurda" a ideia de reconduzir a física moderna à física peripatética, seria possível, ao menos, traçar analogias interpretativas entre ambas, evidenciando a atualidade da última. Cf. o último parágrafo da seção 4 .
} 
experimental de Galileu e Pascal. A falência do mecanicismo é parcial, porque, se as especulaçóes metafísicas e reducionistas sofreram contínuos golpes da experiência, caindo em descrédito, em seu bojo achava-se o desejo de inteligibilidade matemática, cujo destino seguia em sentido oposto. A aspiração matematizante de Galileu e Descartes servia, a cada dia com maior evidência, para estruturar uma ciência de natureza distinta daquela que eles tentaram fundamentar. Desconhecendo o quadro geral da evolução das teorias, não suspeitaram que, séculos mais tarde, quando suas ontologias já haviam sido abandonadas, sua matemática seria utilizada na justificação de uma ciência de caráter fenomenológico antirreducionista ${ }^{8}$.

$\mathrm{O}$ artigo sobre a evolução das teorias físicas mantém estreita analogia com outra obra, de maior extensão, publicada sete anos depois, L'évolution de la mécanique. Numa argumentação deveras similar à anterior (o que nos exime de alguma profundidade analítica), Duhem busca justificar historicamente a adoção da versão generalizada da termodinâmica, cuja essência se funda na ampliaçáo do conceito de movimento, de forma que este seja capaz de abranger tanto as modificaçóes de propriedades de ordem física quanto as de ordem química. Isso significa aceitar que um sistema pode ter suas propriedades químicas alteradas, sem que ponderaçóes sobre o movimento físico (local) de suas partes entrem em jogo 9 . Do ponto de vista do antigo modelo mecanicista, não apelar para uma explicação microscópica do nível macroscópico era o

\footnotetext{
${ }^{8}$ Duhem assume sem receio que o mecanicismo de nuança realista tenha favorecido o desenvolvimento da física matemática, a partir do século XVII, embora sempre tenha se negado a confundir a física teórica, definida como física matemática, com quaisquer teorias mecânicas (DUHEM, 1989a, p. 22-25). Destarte, o nascimento da ciência moderna corrobora a tese de que o mecanicismo andava de par com o matematismo; o seu desenvolvimento, entretanto, evidencia a acidentalidade da conjunçáo inicial, uma vez que a ruína do processo de mecanização da física tende a corroborar a versão instrumental da física-matemática, referendando, acredita ele, a sua própria visão (tanto numa como noutra, a matemática preservará a sua importância fundamental). Como tudo em Duhem, é preciso fixar datas com o objetivo de marcar a evolução de seu pensamento: a essa altura, ele ainda não havia descoberto a ciência medieval, algo que alterará a sua concepção sobre a época em que os fundamentos da física clássica teriam sido lançados. Após a referida descoberta, será possível a ele recuar o nascimento da ciência moderna ao medievo e rejeitar a tese de que o nascimento desta tenha ocorrido em um caldo realista/mecanicista.

${ }^{9}$ Um exemplo pode deixar isso mais claro. Tomemos um recipiente de vidro perfeitamente fechado, no qual existem uma determinada quantidade de cloro e outra de hidrogênio. Ao fazermos incidir sobre o recipiente uma luz de fraca intensidade, o hidrogênio e o cloro se combinarão pouco a pouco, para formar o ácido clorídrico, cujas propriedades diferem das propriedades que os elementos isolados tinham antes da síntese. E, contudo, esse movimento químico realizou-se sem que nenhum movimento local fosse observado (DUHEM, 1901, p. 137-138). Como Duhem reafirma inúmeras vezes, a noção de movimento na termodinâmica idealizada por ele se aproxima da noçáo geral de mudança, em Aristóteles, o que lhe faculta classificar a variação da temperatura de um corpo ou do brilho de uma
} 
mesmo que desistir de conhecer o real em sua intimidade, permanecendo no nível das qualidades sensíveis. Numa palavra: representava um retrocesso explicativo, a manutenção de uma superficialidade descritiva.

Novamente, parte da resposta do físico francês consiste em exaltar a orientação das teorias na direção de uma física das qualidades, cujo arquétipo se encontraria na doutrina peripatética. Tal como antes, essa orientação surge como um resultado histórico náo esperado pelos criadores da mecânica moderna. A retomada das "tradiçôes da Escola" à qual Duhem alude representa exatamente uma "[...] contra-revolução, oposta à revolução cartesiana" (DUHEM, 1903, p. 345 , p. 89), cujo significado íntimo expressa uma correção de rota. Nesse movimento de "reação" em que algo do passado é recuperado, entrevemos uma crítica à noção de progresso linear. O que propriamente se recupera não são as relaçôes fenomenológicas obtidas pelos cientistas, mas o espírito metodológico que preservava o distinguo abolido pelo século XVII, e que condicionava a física a salvar os fenômenos (DUHEM, 1989b, p. 54). Decerto que algo se conserva. Se as teorias mecânicas caíram, umas após as outras, passando por reformulaçôes consecutivas, a linguagem matemática que lhes dava forma permanece como uma aquisição imprescindível. A transitoriedade das teorias mecânicas não implica o abandono da física matemática (DUHEM, 1903, p. 198-199). O impulso para a matematização da física no século XVII junge-se à cosmovisão mecanicista, todavia, a reescrita das conquistas que se seguiram desde o século XVII, em uma linguagem qualitativa, elimina a suposta essencialidade de tal vínculo. $\mathrm{O}$ fato de a edificação da física matemática ter ocorrido durante o auge do mecanicismo prova que mesmo esse amplo movimento, fadado ao declínio, não foi em vão:

Através das vicissitudes que derrubam as teorias efêmeras umas sobre as outras, uma Ideia diretriz parece velar para que nenhum esforço sincero na direção da verdade seja vão ou estéril. O criador consciente de uma doutrina mecânica é também o precursor inconsciente das doutrinas que a substituirão. (DUHEM, 1903, p. 345-346, grifo nosso).

Eis um dos aspectos mais interessantes da filosofia da história de Duhem: os homens trabalham de modo inconsciente, ignorantes do seu legado, como que servindo a um propósito que lhes é desconhecido, e, com a condição de que seus esforços sejam sinceros, a utilidade mínima de suas realizaçóes

fonte luminosa como movimentos (DUHEM, 1896, p. 467). Nesse sentido, o movimento não se opõe mais ao repouso, mas ao equilíbrio (DUHEM, 1894, p. 222). 
estará garantida como forma de recompensa. Não sendo apenas dos homens, a história duhemiana possui um aspecto moral. O zelo com o qual a Ideia diretriz conduz a evolução da mecânica faz com que a termodinâmica seja, também, herdeira das doutrinas mecânicas que ela substitui.

Talvez Jaki (1984, p. 381) esteja certo quando supóe que o uso da expressão "Ideia diretriz", muito provavelmente emprestada de Claude Bernard, seja produto de uma circunspecção provocada pelo conhecimento da orientação eminentemente científica dos leitores habituais da Revue générale. Mas é importante ressaltar que, não obstante a referência à "Ideia diretriz" preservar uma generalidade menos comprometedora que o "Aquele" do artigo anterior, suas funções são as mesmas ${ }^{10}$. Ademais, nenhumas dessas referências podem ser classificadas exatamente como "provas" da existência de Deus. Duhem simplesmente atribui a uma potência superior o regulamento da evolução das teorias, mas em nenhuma circunstância procura organizar o seu discurso de modo a que a evolução histórica sirva de sustentáculo para a crença em uma Providência. Em ambas as ocasiôes, assume-se de antemão a Sua existência. $\mathrm{O}$ mesmo náo acontece com o nosso próximo caso.

\section{LES ORIGINES DE LA STATIQUE - O ARGUMENTO EM SI}

A formulação mais detalhada e explícita do papel desempenhado por Deus no decurso da história é encontrada nas conclusôes de Les origines de la statique. Projetada para ser mais uma reconstrução histórica nos moldes de L'évolution de la mécanique, Les origines sofreu uma das maiores transformaçóes que uma obra publicada inicialmente em artigos sequenciados poderia sofrer ${ }^{11}$.

\footnotetext{
${ }^{10}$ Similaridade que abarca as conclusōes de Les origines de la statique, onde Bernard será expressamente referenciado. A evocação de Bernard inspira cuidados, suposto que parece haver ao menos uma importante diferença acerca do estatuto da "ideia diretriz" entre os autores. Para o fisiólogo, afirma Bergson (2006, p. 239-240), essa ideia não é uma força, capaz de realizar trabalho efetivo e agir sobre as demais forças físicas e químicas, alterando a sua configuração; ela é um "princípio de explicação" da organizaçấo das partes com o todo que caracteriza o organismo já constituído. A concepção duhemiana da história contida no texto examinado admite, para além de um princípio que explique como a ciência atingiu o estado atual, que a ideia diretriz seja ativa, que ela, como veremos na próxima seçáo, torne benéficos os próprios erros. Duhem presume que essa atividade seja parte constituinte da evolução científica. Agradecemos a um dos pareceristas, por ter chamado nossa atenção para a noção bernardiana de ideia diretriz. Uma comparação mais aprofundada poderá ser feita em outra ocasiāo.

${ }^{11}$ O primeiro artigo da série veio a público em outubro de 1903, na Revue des questions scientifiques, e o último, em julho de 1906, perfazendo um total de 11 fascículos. O segundo, cuja publicaçáo devia dar-se em janeiro de 1904, só foi publicado no trimestre seguinte, certamente em função da descoberta dos manuscritos medievais sobre a estática, a qual deve ter ocorrido nos últimos meses de 1903 . As
} 
Seu ponto de partida pressupunha a inexistência de uma estática medieval genuína, inovadora; seu ponto final conclui a favor das origens medievais da estática moderna. A descoberta inesperada da estática medieval alterou a ordenação dos capítulos da própria obra que ainda não haviam sido escritos, modificou substancialmente o rumo das publicações duhemianas que se seguiram e fomentou os estudos subsequentes sobre a ciência medieval.

É contra a “[...] história clássica, falseada por prejuízos e distorcida por simplificaçóes deliberadas" que Duhem (1905-1906, v.2, p. 278) direciona os seus ataques. Essa história "insensata", segundo a qual a ciência teria padecido de uma brusca estagnação ao fim da Antiguidade, para renascer somente após o fim da Idade Média, precisaria ser reescrita com as descobertas recentes. A imagem que a posteridade cunhou do Renascimento científico não condiria com a realidade: "No curso da evoluçáo pela qual a ciência humana se desenvolve são muito raros os nascimentos súbitos e os renascimentos repentinos." (DUHEM, 1905-1906, v.2, p. 278-279). O desenvolvimento da estática patenteia certo gradualismo evolutivo que ignora desaparições e reapariçóes completas. Imaginar o contrário seria permanecer na superficialidade das coisas, tão frequente nos manuais ${ }^{12}$. O gênio isolado, absolutamente criativo, dissolve-se na intricada trama dos fatos - algo essencial para afastar uma "história discreta", demasiado humana, e impelir à aceitação de uma história evolutiva, segundo a qual para todo resultado científico específico uma conjunção de pequenos esforços prévios e, por vezes, imperceptíveis, foram necessários. Cada estágio da evolução da estática encerra, por conseguinte, um emaranhado de afluentes - dir-se-ia, de precursores - que o torna progressivamente mais complexo. Complexificando-se paulatinamente, a ciência é atravessada pelas influências anteriores, revelando uma transmissáo contínua do conhecimento, de modo que duas seriam as principais características de sua marcha - a continuidade e a complexidade. Sem tais atributos, como veremos, a prova duhemiana não se sustentaria.

conclusóes de Les origines, por sua vez, carregam a data de outubro de 1905. Com efeito, Duhem esperava escrever um único volume, mas o projeto original foi alterado por conta da descoberta das contribuições medievais e resultou no acréscimo de um segundo volume. Para maiores detalhes sobre a descoberta, cf. Leite (2015).

${ }^{12}$ A crítica aos manuais é uma constante nos escritos duhemianos. No Système du monde, ela se tornará ainda mais acerba, especialmente quando a obra se voltar, em seus volumes finais, para a transmissão do legado parisiense do século XIV, o qual se teria enegrecido em função da simplificação manualesca. Náo por acaso, o período que Duhem classifica como a decadência da Escolástica é caracterizado pelo predomínio dos manuais (DUHEM, 1954-1959 [1913-1959], p. 58, p.130). 
Não creiamos, porém, que para Duhem continuidade signifique ausência de inovação. Bem pouco do que os sábios helênicos conheciam foi transmitido pelos árabes à Idade Média ocidental. Por felicidade, os escombros herdados dos gregos bastaram para que sua inteligência pudesse ser fecundada e para que, desde pelo menos o século XIII, Jordanus de Nemore, o principal personagem do primeiro volume de Les origines, e sua escola pudessem abrir novas vias, desconhecidas pelo intelecto grego (DUHEM, 1905-1906, v.2, p. 281); cf. também (v.1, p. 98). Todavia, o que o método de Jordanus continha de profícuo ele continha proporcionalmente de incerto. Suas maiores intuições misturavam-se com graves erros, que a duras penas viriam a ser eliminados.

Com da Vinci, Tartaglia, Cardano e outros, a tradição de Nemore prossegue até o século XVI, quando, em sentido inverso, as obras de Arquimedes e Pappus de Alexandria sobre a estática são recuperadas. Duas tradiçôes entram em choque. Os admiradores da ciência helênica buscavam no método arquimediano a segurança dedutiva que eles não enxergavam no método utilizado pelos seguidores da escola de Jordanus. Numa "reação imoderada" (DUHEM, 19051906, v.1, p. 225) de repúdio aos erros remanescentes desta última, a nova escola de Guidobaldo del Monte, Benedetti e Stevin relegou a um plano inferior a generalidade e a fecundidade dos axiomas da estática medieval. Sob o pretexto de tornar a estática mais pura, continua Duhem, a nova escola empobreceu-a, dado o caráter particular dos axiomas adotados pelo siracusano, nos quais ela se apoia. A prevalência do "espírito geométrico" imbuído na doutrina de inspiração arquimediana obliterou a doutrina adversária: "No fim do século XVI, pois, quase nada subsistia na estática daquilo que o gênio próprio do ocidente havia produzido espontaneamente." (DUHEM, 1905-1906, v.2, p. 283); cf. também (v.1, p. 210 212). O culto do rigor impecável fez com que o bebê fosse jogado fora com a água do banho, com que a estática precisasse ser reconstruída. Continuidade, bem o vemos, não significa igualmente ausência de perdas epistêmicas, de "eclipses temporários" (DUHEM, 1905-1906, v.2, p. 267). Acometido pela cegueira de um passado recente, o espírito moderno jacta-se injustamente de estar a inovar quando, em realidade, não faz muito mais do que resgatar o conhecimento de seus precursores. Galileu, Stevin, Roberval e Descartes não estariam a criar um novo saber, mas a restaurá-lo (DUHEM, 1905-1906, v.2, p. 284-285); cf. também (v.1, p. 193, p. 235). Sua originalidade é aparente.

É esse movimento que nos interessa no arrazoado duhemiano. O retorno a Arquimedes faz-se a expensas de perdas epistêmicas iniciais, as quais serão sanadas quando os modernos redescobrirem o que foi por eles mesmos 
esquecido. $\mathrm{O}$ desvio inicial passa por uma recondução que faz coincidir os "novos" resultados com aqueles que já haviam sido obtidos. O curso da ciência é, então, normalizado.

Após atestar que o princípio dos deslocamentos virtuais estava contido em "germe" nas linhas em que Jordanus de Nemore demonstrava a lei do equilíbrio da alavanca ${ }^{13}$, Duhem (1905-1906, v.2, p. 286) acrescenta:

À medida que a gradual evoluçấo de uma verdade prossegue e se conclui, a ciência é o teatro de um fenômeno náo menos interessante, mas mais estranho; uma doutrina falsa se transforma pouco a pouco em um princípio muito profundo e exato; parece que uma força misteriosa, atenta ao progresso da estática, sabe tornar igualmente benéficos a verdade e o erro. (Grifo nosso).

A analogia entre o retorno às descobertas da Escola de Jordanus e o retorno à física das qualidades, descritos em "L'évolution des théories physiques" e em L'évolution de la mécanique, é flagrante. A característica principal que unifica os três excertos destacados até o momento é exatamente a utilidade dos esforços dos teóricos, inclusive de seus erros. Nesse percurso progressivo em que as doutrinas se tornam lentamente mais exatas, nada parece ser em vão. De início, esse fenômeno apresenta-se como "estranho", e a explicação imediata não é muito elucidativa, porquanto o francês se valha de uma suposta "força misteriosa", em uma primeira aproximação. Os progressos da estática são conduzidos por uma força cuja natureza não é determinada, embora sua função o seja - é a ela que se devem os progressos da estática na direção da verdade. Contudo, a que erros alude o autor?

Duhem não identifica com precisão em que consistem tais erros, e isso certamente dificulta uma resposta precisa. Vez por outra, os erros podem ser entendidos como "formais", isto é, erros específicos de representação ou

\footnotetext{
${ }^{13}$ A demonstração da lei do equilíbrio da alavanca feita por Jordanus, em seu Elementa Jordani Super Demonstrationem, pressupunha implicitamente a seguinte asserçăo: "O que pode elevar um dado peso a uma dada altura pode também elevar um peso $\mathrm{k}$ vezes maior a uma altura k vezes menor" (DUHEM, 1905-1906, v.1, p. 121, v.2, p. 281). É sobre essa asserção, afirma Duhem, que Descartes fundará a sua estática, e que, devido aos trabalhos de Jean Bernoulli, se tornará o princípio dos deslocamentos virtuais. É ela, inclusive, a asserção cujo esquecimento ou recusa por parte da escola rigorista é reprovado por Duhem (1905-1906, v.2, p. 267). No método dos deslocamentos virtuais, o historiador francês celebrava sobretudo a generalidade e capacidade de síntese. Dele, consoante a exposição feita por Lagrange, em sua Mécanique analytique, derivam os demais princípios da ciência do equilíbrio, a saber, a lei do equilíbrio da alavanca e a lei da composição de forças, além das propriedades do plano inclinado, os quais, antes de Lagrange, haviam alternadamente fundamentado o estudo da estática (DUHEM, 1905-1906, v.2, p. 273).
} 
formalização (uma relação incorreta entre grandezas teóricas). Por vezes, o erro decorre de um estilo ou tendência mais geral, em algum excesso que persiste por séculos e reorienta a evolução da ciência em um sentido que se distancia do equilíbrio ideal. Pensamos ser este o caso mais importante encontrado em Les origines. $\mathrm{O}$ excesso de rigor formal, a hipertrofia do espírito geométrico, em detrimento da intuição criativa, representou um retardo no progresso da estática (DUHEM, 1905-1906, v.1, p. 210). Verdades germinantes, misturadas com proposiçóes errôneas, foram descartadas juntamente com estas, sem o emprego de um claro e ponderado discernimento. A escola de Jordanus, salienta Duhem, foi vítima do ideal de rigor desmedido imperante no século XVI. Esse foi o erro da nova escola. Por outro lado, a seleção entre as proposiçốes verdadeiras e falsas era necessária, e ninguém estava mais bem preparado para essa tarefa do que os espíritos preocupados com as sólidas demonstraçôes. Na primeira metade do século XVII, a triagem a que se refere nosso autor representa, nem mais, nem menos, a reconstrução de uma estática vigorosamente fundamentada e independente da dinâmica, a qual já não podia mais ser nem a claudicante dinâmica peripatética, nem a dinâmica moderna, em via de construção (DUHEM, 1905-1906, v.1, p. 349). A autonomização da estática, liberta das hipóteses duvidosas de uma dinâmica vacilante, foi obra do espírito geométrico. Esse foi o acerto da nova escola. A obra de Descartes, rigorosa e fecunda, é, pois, o fruto maduro resultante de duas tradiçóes opostas que, ali, se equilibram: a tradiçáo de Jordanus e a tradição rigorista, arquimediana, retomada no século XVI. Atendendo a todas as necessidades intelectuais, para ela confluem em harmonia os esforços já seculares das duas correntes (DUHEM, 1905-1906, v.1, p. 349).

A últimas páginas de Les origines de la statique manifestam a eloquência de quem deseja franquear a abertura de um novo capítulo, outrora incrível, na história da ciência. $\mathrm{O}$ recurso às metáforas, especialmente as inspiradas na biologia, é constante sob a pena duhemiana. Suas teses mais estimadas são repetidas vezes ilustradas dessa maneira ${ }^{14}$. A metáfora mais comum, em seus escritos, é a da semente que se desenvolve até atingir o estado adulto, apto a render seus frutos. Nas conclusōes de Les origines, Duhem aproxima novamente o trabalho do historiador do trabalho do naturalista, ao afirmar que a semente está para a planta adulta assim como a teoria de Nemore está para as teorias contemporâneas da estática. Não é possível reconhecer a

\footnotetext{
${ }^{14}$ A noção de classificação natural, de suma importância para a metodologia do autor, é apresentada em La théorie physique segundo esse viés (DUHEM, 1981, p. 33). O mesmo já acontecera na crítica duhemiana ao experimento crucial (DUHEM, 1989c, p. 95).
} 
segunda na primeira, exceto se se acompanhar o desenvolvimento contínuo, gradual, entre as formas inicial e final. Daí que ele não hesite em dizer que em uma pequena demonstração de Nemore estavam contidas "em potência" as doutrinas de Lagrange, Gibbs e Helmholtz (DUHEM, 1905-1906, v.2, p. 288); cf. também (v.1, p. 147). Entre os dois estados, de assombrosa disparidade, a filiação somente é acessível a uma história cuidadosa.

Esse "espetáculo", contudo, não é o mais admirável. Não é apenas o contraste entre o antes e o depois que espanta tanto o naturalista quanto o historiador da estática, mas a ordem implicada na própria evolução - o transcorrer dela:

O desenvolvimento que ele [o naturalista] estuda resulta de uma infinidade de fenômenos diversos. É preciso, para produzi-lo, uma série de divisóes celulares, de germinaçóes, transformaçóes, atrofiamentos. Todos esses fenômenos, táo numerosos, variados e complicados, coordenam-se com uma precisão perfeita. Todos concorrem de uma maneira eficaz à formação da planta ou do animal adulto. E, entretanto, os inumeráveis seres que agem nesses fenômenos, as células que proliferam, os fagócitos que fazem desaparecer os tecidos que se tornaram inúteis, não conhecem seguramente o fim ao qual eles se esforçam por atingir. Trabalhadores que ignoram a obra a ser produzida, eles realizam no entanto essa obra com ordem e método. Também o naturalista náo pode evitar procurar, fora e acima deles, um algo mais [je-ne-sais-quoi] que veja o plano do animal ou da planta por vir e que, para a formação desse organismo, faça concorrer a multidão dos esforços inconscientes; com Claude Bernard, ele saúda a ideia diretriz que preside o desenvolvimento de todo ser vivo. (DUHEM, 1905-1906, v.2, p. 289).

A complexidade e o arranjo presentes no desenvolvimento dos seres vivos resulta de uma "infinidade de fenômenos diversos" e, sem embargo, de uma perfeita ordenação de suas partes. A perfeição e o propósito pressentidos na evolução dos organismos, inconscientes acerca do resultado vindouro de seu trabalho, leva o naturalista a indagar-se sobre algo que náo apenas conheça o plano a ser realizado, porém, que seja capaz de fazer convergir os esforços particulares na realização daquele plano. É por intermédio de uma analogia assaz sugestiva que Duhem inicia o movimento seguinte: assim como há uma ordem no desenvolvimento de um organismo vivo, sobretudo nos mais complexos, a qual parece seguir uma finalidade muito bem traçada, a evolução da estática é sede de ordenação semelhante. Cada uma das proposiçôes da estática foi construída por uma multidão de "pesquisas, ensaios, hesitaçôes, discussões, 
contradiçôes", sem que nenhuma dessas tentativas tivesse sido inútil. No limite, como temos observado, até os erros os mais comezinhos constrangem os adversários a esclarecer as suas ideias. São favores ensejados à verdade.

Diante de tamanha complexidade, só uma descrição histórica adequada é capaz de evidenciar a ordem perene sob as etapas sucessivas percorridas pela ciência. Mas ela não deságua senão em outra questão: o que explica aquela ordem em meio à complexidade? Se assumimos que a descrição da ordem difere da explicaçâo de sua causa, algo resta de inexplicado. Afinal, o que faz convergir os esforços de tantos espiritos para uma teoria cada vez mais unificada e perfeita? De onde provém a fecundidade dos erros? O que garante a aproximação pacifica e harmônica entre ideias anteriormente tão heterogêneas?

Como todos esses esforços teriam podido concorrer exatamente à realização de um plano de manobras desconhecido, se esse plano não pré-existisse, resumido com clareza, na imaginação de um arquiteto, e se esse arquiteto não tivesse o poder de orientar e de coordenar o labor dos pedreiros? O desenvolvimento da estática nos manifesta, tanto e mais ainda do que o desenvolvimento de um ser vivo, a influência de uma ideia diretriz. Através de fatos complexos que compóem esse desenvolvimento, nós percebemos a ação contínua de uma Sabedoria que prevê a forma ideal na direção da qual a ciência deve tender e de uma Potência que faz convergir na direção desse fim os esforços de todos os pensadores; em uma palavra, nós reconhecemos neles a obra de uma Providência. (DUHEM, 1905-1906, v.2, p. 290, grifo nosso).

Com as palavras acima, Duhem oferece à apologética cristã (teísta) uma nova variante do argumento do desígnio. Em princípio, seu argumento nos é apresentado por via de uma analogia entre a evoluçấo da estática com os seres vivos. A evolução teórica contínua, complexa e maravilhosamente ordenada, por vezes "consiliada" ${ }^{15}$, leva-nos a suspeitar que existe, por trás da superfície contrastante notada, um fim especifico para o qual tenderam, guarnecidos por uma "ação contínua", todos os esforços realizados do passado até o presente. Ora, se há uma finalidade que guia toda aquela harmonia, onde ela reside? Não pode ser na mente dos próprios físicos, pois como a história nos mostra, eles são, assim como as células de um organismo complexo, inconscientes sobre o lugar que sua obra ocupará no esquema teórico ainda por vir. Dado que o futuro lhes é desconhecido, segue-se que os executores do planejamento

\footnotetext{
${ }^{15}$ Entendo aqui por "consiliência" uma espécie de aproximação coerente e insuspeitada entre duas ou mais teorias tidas até então como desconexas. A ocorrência de consiliências serve de premissa para a conclusão de que a ciência caminha da diversidade para uma unidade sempre crescente.
} 
que se concretiza historicamente não são os seus próprios projetistas. Uns são pedreiros - outro será o arquiteto. Logo, a consciência do plano pertence exclusivamente ao seu formulador, o qual se situa acima dos homens comuns e ignorantes. Sábio, esse arquiteto conhece previamente o plano a ser realizado; poderoso, ele conduz e faz convergir os esforços particulares para o fim estipulado; bondoso, recompensa até mesmo aqueles que erraram, assegurando à sua obra, desde que elaborada com o desejo "sincero" de obter a verdade, um lugar digno no rol da ciência. Esse autor é a Providência, ou, é preciso reconhecê-lo, o Deus cristão ${ }^{16}$.

O físico sincero, por conseguinte, é orientado pelas mãos de um arquiteto poderoso. O contínuo aperfeiçoamento da ciência revela, com nitidez crescente, um plano imprevisto ao físico enquanto físico, cuja tomada de consciência exige uma visáo distanciada. O reconhecimento desse curso teleológico depende, por conseguinte, da adoção de um ponto de vista temporalmente ampliado. Unicamente depois de observaçôes que considerem longos períodos históricos é que o papel providencial de Deus pode ser apreciado. Como Darbon (1928, p. 507, n. 9) notou, "[...] a análise histórica fê-lo [Duhem] inicialmente descobrir a extrema complexidade da evolução científica. E é somente após tê-la constatado que, admirando a fortuna desse

\footnotetext{
${ }^{16}$ Afirmar que de fato se trate do Deus cristão, quando o próprio Duhem não o faz, só é possível recorrendo a outras passagens nas quais o autor testemunha pública ou privadamente sua fé católica (cf. respectivamente Duhem (1981, p. 414); Jaki (1994); Duhem (1989b, p. 50). Mas a referência mais elucidativa consiste na resenha de L'avenir du christianisme, de Albert Dufourcq, um amigo íntimo. $\mathrm{O}$ tom de aprovaçáo presente nela, para não insistirmos sobre a surpresa que nos causa sua própria escrita (trata-se da única resenha redigida por Duhem de uma obra de história da religião) não deve ser negligenciado. Duhem contrapốe a imagem cristã da história ao que ele denomina teoria racionalista, para a qual a história da humanidade seria o resultado de um encadeamento cego de leis sem finalidade alguma, de um fatalismo insuplantável. O exemplo oferecido desse tipo de teoria é a "seleçấo natural", apresentada segundo uma imagem caricaturesca, para a qual a moral e a religiáo seriam duperies instituídas com o fito de acorrentar os instintos adversários. Segundo essa teoria, nem o indivíduo nem a espécie sobreviverão para sempre. Em breve, o primeiro será dissolvido pelas açóes químicas; num horizonte distante, a segunda se extinguirá num gélido planeta sem vida: "Tal é a história para quem quer abordá-la enquanto zoólogo e jamais enquanto cristáo." (DUHEM, 1904, p. 208). Ao contrário, ao conferir à história uma regência divina, nosso autor atribui um sentido moral a ela. No "dédalo dos fatos históricos”, um fio condutor - a teoria cristã da evolução da Igreja - é o responsável por fazer "reconhecer um plano de admirável unidade no que teria parecido ser obra do acaso" (DUHEM, 1904, p. 207). Em poucas palavras, toda a resenha dedica-se a desenredar suas primeiríssimas linhas, nas quais nos deparamos com o seguinte fragmento dos Pensamentos de Pascal: "Como é belo ver, com os olhos da fé, Dario e Ciro, Alexandre, os romanos, Pompeu e Herodes agirem, sem o saber, para a glória do Evangelho!" (DUHEM, 1904, p. 207). Só assim eliminamos a indeterminação inicial e obtemos uma base para alegarmos que todas aquelas menções oblíquas a que nos reportamos no início da seção 2 tinham por referencial o Deus cristão.
} 
movimento confuso, ele se eleva às vezes à ideia de uma direção providencial”. De fato, os vestígios da ação divina estão espalhadas ao longo dos séculos, e é possível desvendá-los - a história serve de meio de elevação a Deus. É a essa tática inusitada que, posteriormente, Maiocchi (1985, p. 259) chamará de a "sexta via", lembrando as cinco vias tomistas.

Nada há que possa ser objetado contra a descrição de Darbon, o qual, inclusive, considera que os atributos principais da evolução da ciência seriam, para Duhem, a continuidade, a complexidade e a finalidade inconsciente. A inclusão desta última característica é de responsabilidade do próprio Darbon (as duas primeiras já haviam sido mencionadas explicitamente por nosso autor). A essas três características podemos acrescentar ainda a convergência teórica, que condiciona a ciência a uma unidade e generalidade sempre crescentes. É essa mesma convergência que, na Théorie physique e nos dois apêndices de sua segunda edição, será usada em favor do realismo científico (DUHEM, 1981, p. 35, p. 446-453, p. 505-509).

Contudo, caracterizar a prova duhemiana como uma sexta via, tal qual Maiocchi o fez, pode não ser a melhor opçáo. Quanto à forma, ela se assemelha à quinta via de Tomás de Aquino ${ }^{17}$, vale dizer, a via que se convencionou chamar de argumento do desígnio ou teleológico. O que Duhem nos oferta é uma versão desse argumento. Especificamente quanto à matéria, de fato, sua prova guarda certa originalidade, a começar por uma diferença essencial. $\mathrm{Na}$ prova tomista, a ação dos corpos físicos apresenta uma ordenação que não pode ser explicada por uma finalidade intencional inerente a eles, visto que carecem de conhecimento, $\mathrm{e}$ "[...] aquilo que não tem conhecimento não tende a um fim, a não ser dirigido por algo que conhece e que é inteligente”. Em decorrência, a finalidade das coisas que observamos deve resultar de um governo inteligente. Na prova duhemiana, como os agentes do conhecimento são os próprios cientistas, eles mesmos seres inteligentes capazes de açôes intencionais, a introdução de uma nova premissa torna-se necessária para que a existência da Providência possa ser concluída. A premissa adicional é a tese da inconsciência dos cientistas a respeito do lugar que suas realizaçóes

\footnotetext{
${ }^{17}$ A prova tomista é formulada do seguinte modo: "A quinta via é tomada do governo das coisas. Com efeito, vemos que algumas coisas que carecem de conhecimento, como os corpos físicos, agem em vista de um fim, o que se manifesta pelo fato de que, sempre ou na maioria das vezes, agem da mesma maneira, a fim de alcançarem o que é ótimo. Fica claro que nâo é por acaso, mas em virtude de uma intençấo, que alcançam o fim. Ora, aquilo que não tem conhecimento não tende a um fim, a não ser dirigido por algo que conhece e que é inteligente, como a flecha pelo arqueiro. Logo, existe algo inteligente pelo qual todas as coisas naturais são ordenadas ao fim, e a isso nós chamamos Deus." (AQUINO, 2003, p. 168-169).
} 
ocuparão, no quadro geral das teorias. E é no entrosamento harmônico de um complexo de inconsciências individuais que atua o que aparenta ser uma consciência superior. Sem a observância da ordem em uma zona de inconsciências, o argumento se tornaria írrito. Resta visível que não é em alguma perfeição revelada por processos naturais que o argumento duhemiano se assenta, mas na série evolutiva das teorias físicas, definidas como construtos artificiais, humanos. $\mathrm{O}$ argumento fundamenta-se em um nivel superior, pois não se trata de utilizar como explanandum a perfeição vislumbrada no mundo ou em algumas de suas partes, mas aquilo que se diz ou se crê conhecer acerca do mundo - as teorias. Efetivamente, a unidade basilar da prova não é uma teoria isolada, contemplada em separado de sua evolução, mas uma série temporal, preferencialmente longa, de teorias. É esta última que deve ser considerada um sistema teleológico, segundo a expressão de Rowe $(2007 \text {, p. 57 })^{18}$. No entanto, de igual modo, essa série temporal náo basta. Um novo requisito deve ser adicionado: é preciso que se trate de uma sequência bem-sucedida de teorias. De uma evolução do falso para o falso nenhum propósito superior benévolo poderia ser derivado. $\mathrm{O}$ sucesso da ciência aponta para a existência de um sentido evolutivo, muito bem definido, de uma evolução para a verdade - per falsa, ad verum (DUHEM, 1900, p. 251). Os sinais da Providência, desvelados na harmoniosa consonância das mais diversas "verdades", outrora isoladas, num todo complexo, estariam situados no processo convergente, e não em uma teoria ou série qualquer de teorias.

\section{ANÁLISE DO ARGUMENTO DUHEMIANO}

Os vícios que afetam as formulaçóes tradicionais do argumento do desígnio são exacerbados na versão duhemiana. Em primeiro lugar, como é manifesto, a constatação do propósito superior responsável por guiar os esforços inconscientes dos homens deriva de uma reconstrução a posteriori (tal como sucede com o argumento do desígnio) e, assim, padece das fragilidades de um

\footnotetext{
${ }^{18}$ Rowe (2007, p. 57) define um sistema teleológico como "[...] qualquer sistema composto de partes que se encontram arranjadas de tal modo que em condiçóes adequadas funcionam conjuntamente para servir a um determinado propósito". Um automóvel, ou partes suas, mas também o olho humano, as plantas e os animais seriam sistemas teleológicos. Lembremos que Duhem não compara diretamente a teoria a uma planta ou animal; a analogia que lhe interessa é estabelecida entre suas respectivas evoluçóes. Sem que a evolução interviesse, coordenada de cima por uma "força misteriosa" que ultrapassa as consciências individuais, uma teoria continuaria sendo produto tão humano quanto um relógio. Isso talvez explique o porquê da ausência de referências ao relógio de Paley ou a quaisquer artefatos humanos como termos de comparação.
} 
argumento abdutivo ou probabilístico (notável é que Duhem não caracterize a sua versão como probabilística). A peculiaridade, em nosso caso, dá-se no modo como aquela reconstrução é efetuada. A disparidade entre as teorias antigas e as teorias atualmente aceitas tende a ser tamanha que apenas o recurso à narrativa histórica possibilita traçar a filiação entre elas (DUHEM, 1905-1906, v.2, p.288). Dessa maneira, o reconhecimento do legado das obras passadas para o quadro geral da ciência do presente é feito anacronicamente. Se a importância dos erros e da complexidade da evolução teórica é salientada, os resquícios de uma visão whiggista da história são inarredáveis, uma vez que só conhecendo as teorias vitoriosas é possível averiguar o mérito geral do argumento. A versão duhemiana, por conseguinte, só pode ser adequadamente apreciada pelo leitor esclarecido, conhecedor da história da ciência, porque é no movimento temporal da estática que ela granjeia seus princípios, inclusive onde se pode facilmente suspeitar de sua ausência, nos erros. Não basta, como o homem comum, olhar para a perfeiçáo que se apresenta imediatamente aos seus olhos, para vislumbrar uma ordem patente a todos. É preciso saber (quiçá desejar) ver aquilo que não se revela de pronto. A posição de Duhem abre uma nova fronteira aos defensores do argumento do desígnio, pois suas premissas não se localizam na ordem natural (seja física, seja biológica), mas numa ordem epistemológica. Obviamente, essa ordem pode, ela mesma, ser concebida naturalisticamente, como que fazendo parte do mesmo universo das pedras, plantas e animais, entretanto, isso não muda o seu caráter epistemológico. Em última análise, Duhem transforma um argumento que poderia ser usado a favor do realismo científico em um argumento a favor do teísmo, tal como se a existência de um plano prévio, arquitetado por uma Sabedoria capaz de criá-lo e conservá-lo, fosse a melhor explicação para o sucesso da ciência.

Ademais, não há qualquer garantia necessária de que os êxitos observados no passado (a proficuidade dos erros e a convergência teórica), dos quais a agência divina é derivada, prolonguem-se no futuro, que eles não sejam o resultado, se quisermos, de uma grande "coincidência cósmica" temporalmente limitada. Com boa dose de retórica, o texto almeja aliciar o leitor, ao lhe perguntar: "Por que a evolução, da qual essa história nos manifesta a lei, pararia abruptamente?" (DUHEM, 1981, p. 448). A confiança na convergência futura é afirmada com base na convergência passada, como se a parcela pudesse justificar o todo. Ciente da invalidez de sua inferência, Duhem assevera que a história é capaz apenas de nos fazer suspeitar (DUHEM, 1981, p. 460) da legitimidade de nossas expectativas positivas sobre o porvir. Todavia, essa suspeita, mero pressentimento (DUHEM, 1981, p. 459), torna-se inevitável e coercitiva. Se, de início, o rigor 
lógico invalida toda conclusão respeitante ao futuro, num segundo momento, contraposto ao primeiro, nossa natureza leva-nos a continuar esperando pela manutenção da evolução que regula os esforços dos físicos à unidade teórica crescente, de sorte que, mesmo diante do peso da lógica, não conseguiríamos manter-nos indiferentes em relação ao futuro, depois de constatados os êxitos passados (DUHEM, 1981, p. 451). É oportuno relembrarmos aqui as palavras de Pascal, mencionadas em outra ocasião, mas em contexto parecido: "A natureza sustenta a razão impotente e a impede de extravagar até esse ponto." (DUHEM, 1981, p. 154). A natureza insinua-se nas brechas deixadas pela análise lógica, encarregando-se da "justificação" dos juízos de que esta é incapaz. Que exista uma espécie de naturalismo em Duhem é algo indisputável. A tensão - a nosso ver, insolúvel - entre a análise lógica e as intuiçôes inanalisáveis e irresistíveis da natureza é uma das características mais marcantes do pensamento do autor (LEITE, 2007, p. 230-250). Apenas levando em conta essa dualidade, a qual retira da prova duhemiana todo fundamento lógico, é que podemos melhor avaliar seu estatuto.

Em segundo lugar, o argumento do filósofo ampara-se na vigência de uma analogia entre o desenvolvimento dos seres vivos e das teorias ${ }^{19}$. A importância epistemológica que o conceito de analogia adquire em sua obra deve, pois, ser aquilatada. Na Théorie physique, ela é descrita como "[...] o método mais seguro e fecundo" de descoberta (DUHEM, 1981, p. 140), consistindo em um verdadeiro "procedimento de invenção"20 (DUHEM, 1981, p. 142). De modo preciso, a analogia indica um procedimento de ilustraçáo conforme o qual uma teoria serve de base para a composição de outra, e pode ser definida como a semelhança formal entre duas categorias distintas de relaçóes representadas por equaçôes algébricas idênticas. Mas não é só.

\footnotetext{
19 Em função de seu cunho analógico, o argumento duhemiano envolve dois polos: as partes constituintes dos seres vivos, base para as comparaçóes, e as teorias físicas. Dois termos comuns unem os polos: a inconsciência das células e dos cientistas a respeito do plano ordenado que realizam, em meio à complexidade e a agência constante de uma ideia diretriz que os conduz segundo aquele plano.

${ }^{20} \mathrm{Em}$ verdade, para o autor, não existe qualquer conjunto fixo de regras que, quando aplicado, redunde em invençōes teóricas (DUHEM, 1981, p. 144). A invenção genial é vista por ele como uma "revolta" contra um quadro aprisionante de fatores, como métodos enganosos e mestres cujo ensino seria limitado (DUHEM, 1916, p. 151). Uma invençấo pode ser sugerida por uma analogia (DUHEM, 1903, p. 194), pelo estudo da história ou por teorias metafísicas, mas não determinada por estes. Destarte, a analogia representa um procedimento altamente heurístico, embora essencialmente avesso à algoritmizaçấo, dado que depende sobremaneira da perspicácia do físico, sendo, conseguintemente, falível. O caráter falível da analogia ficará mais claro no próximo parágrafo.
} 
À valorizaçáo heurística da analogia enquanto procedimento criativo corresponderá uma desvalorização dela enquanto procedimento demonstrativo. Em mais de uma oportunidade, Duhem explicita a robustez epistemológica da analogia, contrapondo-a à solidez das demonstraçóes matemáticas. Ao passo que, em uma altercação acerca da validade de uma proposição geométrica determinada, a concordância entre as partes deve ser necessária, o debate sobre a vigência de uma relação analógica, pelo contrário, estará sempre aberto à discussão. A analogia não é demonstrada tal como se demonstra dedutivamente um teorema ou uma série de silogismos, mas sentida. Portanto, ela não possui a "força irresistível do silogismo" ou "o peso do princípio de contradição" (DUHEM, 1981, p. 458). Essa característica possibilita que onde alguém afirme vigorar uma analogia, outro, detendo-se nas diferenças, persista legitimamente - em negá-la. Será então impossível classificar a posição de qualquer um dos contendores como absurda, porquanto uma analogia náo pode ser formulada ou definida more geometrico. Ela náo é suscetível de definição, mas de descrição, já que decorre de uma "intuição inanalisável" atinente antes ao espírito de finura que ao espírito geométrico (DUHEM, 1985, p. 76), de modo que ela sempre permanecerá ambígua em algum grau. Conquanto, em algumas circunstâncias, as similaridades analógicas sejam flagrantes e seu reconhecimento se torne forçoso, sua percepção será sempre “relativa, pessoal e variável”. À analogia não cabe o poder da convicção, mas tão-somente o da persuasão, consoante a clássica distinção recuperada pelo autor. Não se pode desejar convencer um adversário por meio dela; pode-se, no entanto, persuadi-lo, atraindo a atenção para "as semelhanças que ele julga importantes" e desviando-a "das divergências que considera negligenciáveis".

$\mathrm{O}$ fato de a analogia não ter o peso de uma demonstração lógica não lhe retira a capacidade de ser articulada para compor uma "prova por analogia" (DUHEM, 1981, p. 457). Um exemplo desse tipo de prova pode ser encontrado em "Physique de croyant", quando, ao expandir o domínio de aplicação da analogia para além das proposiçóes da física teórica, o autor tenciona mostrar que ela pode ocorrer entre sistemas teóricos e sistemas cosmológicos (DUHEM, 1981, p. 453-462). Dessa feita, trata-se de uma relação de semelhança estrutural entre duas "imagens" distintas do mundo, visto que tomadas de pontos de vista diferentes, mas que, no limite, corresponderiam harmonicamente entre si, em função de sua mútua convergência na direção da realidade (DUHEM, 1981, p. 471). Duhem adota a termodinâmica de sua época como base para a comparaçáo com a cosmologia peripatética, com a finalidade de, apoiando-se na segurança consensualmente admitida da primeira, "aumentar a confiança" 
na segunda (DUHEM, 1981, p. 462-472. Lembremos que a cosmologia de Aristóteles fundamentava a metafísica oficial da Igreja). É sintomático que a "prova por analogia", esboçada nas linhas de "Physique de croyant", seja feita em meses contíguos, senão idênticos, àquela de que nos ocupamos neste artigo. Tanto uma como outra recorrem à analogia. Enfim, decidido a arriscar-se abertamente na defesa de sua religiáo, o arroubo metafísico que move Duhem é tanto mais sintomático, porque ele não mais revolverá nenhuma dessas provas em escritos ulteriores. A preservação da coerência interna do pensamento duhemiano impede que aquilo a que chamamos de sua "prova" da existência de Deus possa ser alçado ao patamar de uma demonstração existencial do Mesmo. Suas limitaçóes coincidem com as da persuasão.

\section{CONSIDERAÇÓES GERAIS - A APOLOGÉTICA RELIGIOSA NO HORIZONTE DA HISTÓRIA DA CIÊNCIA}

Escrevendo na virada do século XIX para o século XX, Duhem inserese no contexto do reavivamento do neotomismo propugnado pelo papa Leão XIII, após um período de recuo da Igreja diante do avanço positivista. Dos fiéis católicos treinados nas mais variadas ciências esperava-se que empregassem seu conhecimento com finalidade apologética. Geralmente, duas eram as estratégias apologéticas mais comuns: uma negativa, que consistia em enfraquecer a posição do adversário - no caso, o cientificismo - a partir de seu interior; e uma positiva, a qual intencionava fortalecer a posição da própria Igreja, coletando ou criando argumentos que lhe fossem de algum modo favoráveis. Até que ponto Duhem arrogou deliberadamente a missão recomendada por Leão XIII é matéria sujeita à discussão, embora seja fácil mostrar que ambas as estratégias estejam presentes em sua produção. Na obras epistemológicas, o autor defende insistentemente a estratégia negativa, quando justifica o seu convencionalismo, o qual redundará na distinção entre a física e a metafísica ${ }^{21}$ (MARTIN, 1991; STOFFEL, 2002; LEITE, 2016). Por sua vez, defendemos que, para bem acomodar as consequências do exposto na seção 3, a estratégia positiva deva ser desmembrada em duas categorias, vale dizer; (a) a valorização do papel histórico da Igreja enquanto instituição no nascimento da ciência moderna (de uma óptica mais externa), e (b) a defesa histórica da existência de Deus (de uma perspectiva internalista). Ambas as categorias partem da história, mas fazem uso apologético diferente dela.

${ }^{21}$ Essa estratégia, cujo estudo não está incluído nos objetivos do presente artigo, foi mencionada superficialmente na seção 2 . 
Obra emblemática, Les origines de la statique congrega as duas categorias positivas - e isto a torna singular. A introdução, o corpo do texto e partes da conclusão almejam a desacreditar o prejuízo iluminista segundo o qual o espírito de subserviência, o qual teria aplacado o intelecto numa época dominada pela religião, pouco havia contribuído para o progresso da ciência. Inovador, o retrato duhemiano revela que, em estática, os pensadores medievais transmitiram à modernidade uma obra rica. Futuramente, a partir de meados de 1908, Duhem fará o mesmo, acerca da dinâmica e da astronomia, nos Études sur Léonard de Vinci e em Le système du monde (LEITE, 2015). Entretanto, ao contrário das publicaçóes vindouras, nas páginas finais de Les origines, ele não se satisfez com essa estratégia externa, ultrapassando o terreno da pura análise fatual para adentrar no domínio da filosofia da história. O discurso duhemiano instaura uma estratégia histórico-filosófica de cunho interno, atentando para aquilo que une as realizaçóes individuais descritas no transcorrer do volume. Estas são, em última instância, explicadas "do alto”. É nesse ponto que o historiador cede lugar ao filósofo da história.

Ao passo que as reflexóes acima incluem nosso autor numa longa tradição apologética que remonta à Antiguidade, até atingir uma pluralidade de variantes entre os teístas contemporâneos, sua argumentação ainda permanece inteiramente esquecida nos recortes cronológicos que introduzem ou analisam o argumento do desígnio. Um menoscabo que tende a produzir leituras coxas e classificaçóes questionáveis. Assim o afirmamos, porque, não raro (KRAGH, 2008, p. 114; HESS; ALLEN, 2008, p. 58), Duhem é visto como um defensor da tese da independência, conforme a tipologia de Ian Barbour (2000, p. 7-38). Expliquemos: segundo o físico chinês, a tese da independência sustenta que a ciência e a religião tratam de domínios distintos, mas complementares, da realidade, porque seus métodos, objetivos e linguagens seriam incomensuráveis, de sorte que nenhuma das duas áreas poderia ser usada para fundamentar ou infirmar a outra. Cada disciplina seria regulada por sua esfera valorativa própria, e teria uma legitimidade restrita. A tese da independência coincide com a estratégia apologética negativa que vimos no início destas consideraçôes finais. Todavia, levando em conta as análises da seção 3, uma circunscrição deverá ser efetuada. Pelo menos no nível da história interna da ciência, Duhem pode ser qualificado como um adepto da tese da integração, ainda conforme a classificação de Barbour. Em resumo, os integracionistas defendem que a ciência, genericamente considerada, é capaz de fornecer um apoio à religiāo, já que ambas poderiam chegar, por vias diferentes, aos mesmos resultados. Os partidários da teologia natural e, não 
por acaso, do argumento do desígnio, seriam integracionistas. Sabemos que Duhem nunca rejeitou a teologia natural (cf. LEITE, 2016). O que ele sempre repudiou é que a física teórica, na exata medida em que é matemática, teórica e convencional, pudesse ser usada para demonstrar ou atacar uma cosmologia particular, embora jamais tivesse imposto esses ditames à história da física teórica (DUHEM, 1981, p. 413-472; 1989b). Conquanto proposições da física teórica não possam servir de premissa em argumentos teológicos, algo diferente ocorre com as proposiçóes pertencentes ao escopo da história da ciência. $\mathrm{O}$ argumento que aqui apresentamos se baseia não propriamente em hipóteses concernentes à estática, mas no modo característico de sua evolução na direção de teorias mais adequadas. A distinção entre a física teórica e a metafísica ou teologia não é ameaçada, quando se pondera que, para o professor de Bordeaux, a história da ciência é igualmente uma ciência e, além disso, que a física e a história são ciências de naturezas distintas que seguem métodos diversos ${ }^{22}$. Não há, assim, como sugeriram Kragh (2008, p. 390) e Deltete (2011, p. 23, n. 6), uma inconsistência no uso apologético da história da ciência. Como a adesão à tese integracionista não implica a restrição do conjunto da ciência à física teórica, Duhem pode ser reputado, em sentido restrito, um adepto do integracionismo.

LEITE, Fábio Rodrigo. An argument for the existence of God formulated by Pierre Duhem. Trans/form/ação, Marília, v. 39, n. 4, p. 33-58, Out./Dez., 2016.

\begin{abstract}
The aim of this paper is to examine what we believe to be an original proof of the existence of God in the work of Pierre Duhem. We think that the originality of this proof consists especially in the assumptions used by the French philosopher in his argumentation. Regarding the form, it resembles the well-known design argument, but his version is characterized by seeking in the history of physical theories the matter from which the existence of a Providence is derived. It is the complex evolution of theories and, despite it, its amazing progress towards ever more perfect theories that serves as the premise for Duhem's way of access to God. Everything goes as if it had been a divine preordainment and an intrinsic goal ruling the evolution of theories.
\end{abstract}

KEYWORDS: History. Physical theories. Stastics. Intelligent design. God.

${ }^{22}$ Impossível alongarmo-nos sobre a concepção duhemiana da natureza da história enquanto disciplina (historia rerum gestarum) ou enquanto conjunto de acontecimentos (res gestae). Basta que frisemos que, em La science allemande, obra de maturidade, a história é conceituada como uma ciência cujas hipóteses seriam empiricamente testáveis com base em acontecimentos, textos, relatos etc. Não bastasse, sua filosofia da história coaduna com a existência de leis históricas. Interessados poderão consultar, a respeito: Leite (2012, p. 138-169); Chiappin e Leister (2009). 


\section{REFERÊNCIAS}

AQUINO, T. Suma teológica. v.1. 2. ed. São Paulo: Loyola, 2003 [2001].

BARBOUR, I. When science meets religion: enemies, strangers, or partners? New York: Harper Collins, 2000.

BERGSON, H. A filosofia de Claude Bernard. In: O pensamento e o movente. Sáo Paulo: Martins Fontes, 2006. p.235-243.

BROUZENG, P. Duhem: science et providence. Paris: Belin, 1987.

CHIAPPIN, J.; LEISTER, C. A filosofia da história da Duhem: natureza e função. Revista de História, v.161, p. 245-273, 2009.

DARBON, A. L'histoire des sciences dans l'oeuvre de P. Duhem. In: MANVILLE, O. (Ed.). L'oeuvre scientifique de Pierre Duhem. Paris: Feret et Fils, 1928. p.499-548.

DELTETE, R. Homme de science, homme de foi: Pierre Duhem on science and religion. Metascience, v.20, p.18-25, 2011.

DUHEM, P. Commentaire aux principes de la thermodynamique. Troisième partie: les équations générales de la thermodynamique. Journal de Mathématiques Pures et Appliquées, n.10, p.207-285, 1894

. L'évolution des théories physiques du XVIIe siècle jusqu'à nos jours. Revue des Questions Scientifiques, n.40, p.463-499, 1896.

. Théorie et pratique. Revue Philomathique de Bordeaux et du Sud-Ouest, v.3, n.6, p.250-262, 1900.

- Sur quelques extensions récentes de la statique et de la dynamique. Revue des Questions Scientifiques, n.50, p.130-157, 1901.

. L'évolution de la mécanique. Paris: Joanin, 1903.

. L'avenir du christianisme. Revue de Philosophie, v.4, n.1, p.207-215, 1904.

. Les origines de la statique. Paris: Hermann, 1905-1906. 2v.

. La valeur de la théorie physique. Revue Générale des Sciences Pures et Appliquées, v.19, n.1, p.7-19, 1908.

. La science allemande. Paris: Hermann, 1915.

. Science allemande et vertus allemandes. In: PETIT, G.; LEUDET, M. (Ed.). Les allemands et la science. Paris: Alcan, 1916. p.137-152.

Le système du monde: histoire des doctrines cosmologiques de Platon à Copernic. Paris: Hermann, 1954-1959 [1913-1959]. 10v.

La théorie physique: son objet et sa structure. 3. ed. Paris: Vrin, 1981 [1906]. 
Études sur Léonard de Vinci: ceux qu'il a lus et ceux qui l'ont lu. Paris: Archives Contemporaines, 1984 [1906-1913]. 3v.

. Le mixte et la combinaison chimique: essai sur l'évolution d'une idée. Paris: Fayard, 1985 [1902].

Algumas reflexóes sobre as teorias físicas. Ciência e Filosofia, v.4, p.13-37, 1989a [1892]. (Original publicado em 1894). em 1893).

. Física e metafísica. Ciência e Filosofia, v.4, p.41-59, 1989b. (Original publicado

. Algumas reflexóes acerca da física experimental. Ciência e Filosofia, v.4, p. 87-118, 1989c. (Original publicado em 1894).

HESS, P.; ALLEN, P. Catholicism and science. Westport (USA): Greenwood, 2008.

HILBERT, M. Pierre Duhem and neo-thomist interpretations of physical science. Toronto, 2000. Tese (Doutorado em Filosofia) - Institute for the History and Philosophy of Science and Technology, University of Toronto, Canadá, 2000.

JAKI, S. Uneasy genius: the life and work of Pierre Duhem. Dordrecht; Boston; Lancaster: Martinus Nijhoff, 1984.

. (Ed.). Lèttres de Pierre Duhem à sa fille Hélène. Paris: Beauchesne, 1994.

KRAGH, H. Entropic creation: religious contexts of thermodynamics and cosmology. Burlington (USA): Ashgate, 2008.

LEITE, F. A metodologia do senso comum: um estudo da metodologia científica de Pierre Duhem. 2007. 271f. Dissertação (Mestrado em Filosofia) - Faculdade de Filosofia, Letras e Ciências Humanas, Universidade de São Paulo, São Paulo, 2007.

- Um estudo sobre a filosofia da história e sobre a historiografia da ciência de Pierre Duhem. 2012. 460f. Tese (Doutorado em Filosofia) - Faculdade de Filosofia, Letras e Ciências Humanas, Universidade de São Paulo, São Paulo, 2012.

A gênese e a persistência do historiador medieval: o caso de Pierre Duhem. Revista Brasileira de História da Ciência, v.8, n.2, p.26-43, 2015

Sobre las relaciones epistemológicas entre la física teórica y la metafísica en la obra de Pierre Duhem. In: MÁRQUEZ, V. (Org.). Pierre Duhem: entre física y metafísica. Barcelona; Ciudad Juárez: Anthropos Editorial; Universidad Autónoma de Ciudad Juárez, 2016. p.89-124.

MAIOCCHI, R. Chimica e filosofia: scienza, epistemologia, storia e religione nell'opera di Pierre Duhem. Firenze: La Nuova Italia, 1985.

MARTIN, R. Pierre Duhem: philosophy and history in the work of a believing physicist. La Salle: Open Court, 1991. 
OTA,N.K.

NYE, M. Jo. The moral freedom of man and the determinism of nature: the catholic synthesis of science and history in the "Revue des Questions Scientifiques". British Journal for the History of Science, v.9, n.3, p.274-292, 1976.

PAUL, H. The edge of contingency: French catholic reaction to scientific change from Darwin to Duhem. Gainesville: University Press of Florida, 1979.

REY, A. La philosophie scientifique de M. Duhem. Revue de Métaphysique et de Morale, v.12, n.4, p.99-744, 1904.

ROWE, W. Philosophy of religion: an introduction. 4. ed. Belmont: Wadsworth, 2007.

STOFFEL, J-F. Le phénoménalisme problématique de Pierre Duhem. Bruxelles: Académie Royale de Belgique, 2002.

Recebido em 02/12/2015

Aceito em 11/04/2016 